Revue bibliographique pour le domaine irano-aryen

Volume 37-38-39 | 2018

Comptes rendus des publications de 2014-2016

\title{
Nicholas Sims-Williams. A Dictionary: Christian Sogdian, Syriac and English
}

\section{Christelle Jullien}

\section{(2) OpenEdition}

1 Journals

\section{Édition électronique}

URL : http://journals.openedition.org/abstractairanica/42944

DOI : 10.4000/abstractairanica.42944

ISBN : 1961-960X

ISSN : 1961-960X

Éditeur :

CNRS (UMR 7528 Mondes iraniens et indiens), Éditions de l'IFRI

Référence électronique

Christelle Jullien, « Nicholas Sims-Williams. A Dictionary: Christian Sogdian, Syriac and English», Abstracta Iranica [En ligne], Volume 37-38-39 | 2018, document 1, mis en ligne le 30 décembre 2018, consulté le 28 septembre 2020. URL : http://journals.openedition.org/abstractairanica/42944 ; DOI : https://doi.org/10.4000/abstractairanica.42944

Ce document a été généré automatiquement le 28 septembre 2020

Tous droits réservés 
Nicholas Sims-Williams. A Dictionary: Christian Sogdian, Syriac and English

Christelle Jullien 


\section{RÉFÉRENCE}

Nicholas Sims-Williams. A Dictionary: Christian Sogdian, Syriac and English. (Beitrage zur Iranistik), Wiesbaden: Reichert Verlag, 2016, 408 p. ISBN 9783954901753.

1 L'A. offre un outil très précieux pour connaître la langue sogdienne, mais aussi à travers elle la langue syriaque puisque beaucoup de textes de cette littérature ont été transmis en sogdien. Il s'agit surtout d'une production hagiographique, ascétique et liturgique chrétienne. Le sogdien a parfois sauvegardé des récits par ailleurs perdus dans leur langue d'origine, ou des versions plus anciennes que celles actuellement conservées en syriaque. Le dictionnaire est subdivisé en 2 parties, précédées par une introduction explicative très claire (p. 7-10) et des listes d'abréviations, de références bibliographiques et d'éditions des versions parallèles des textes syriaques cités ( $p$. 11-20). La première partie s'ordonne à partir des lemmes en sogdien : il s'agit d'une liste complète de tous les mots attestés dans les textes chrétiens de la littérature en sogdien recensés à ce jour et publiés, avec leurs variantes orthographiques, lorsqu'elles existent. À cela s'adjoint une analyse des formes fléchies ; l'A. donne leurs équivalences dans les textes parallèles correspondants en syriaque. La seconde partie présente le matériau à partir des lemmes en syriaque. Ces deux parties sont complémentaires et interdépendantes: elles permettent de rendre compte de la transmission d'un mot d'une langue à l'autre. L'ouvrage s'achève par un index exhaustif des mots en anglais.

2 Cet instrument de travail sera utile non seulement aux syriacisants et/ou aux spécialistes de sogdien, mais aussi aux iranistes, car l'A. a eu soin de faciliter l'accès aux matériaux pour les usagers (chercheurs, universitaires, étudiants) qui ne connaissent pas forcément le syriaque et/ou le sogdien. Il intéresse tous ceux qui travaillent sur des questions de linguistique, d'histoire de l'Iran ou plus largement du Moyen-Orient.

\section{AUTEURS}

\section{CHRISTELLE JULLIEN}

CNRS, Mondes iranien et indien, Paris 